\begin{tabular}{|c|l|}
\hline Title & Transient change in the shape of premixed burner flame with the superposition of pul sed dielectric barrier discharge \\
\hline Author(s) & Zaima, Kazunori; Sasaki, Koichi \\
\hline Citation & $\begin{array}{l}\text { Japanese Journal of A pplied Physics (JJA P), 55(8), 086201 } \\
\text { https://doi.org/10.7567/JJA.55.086201 }\end{array}$ \\
\hline Issue Date & 2016-08 \\
\hline Doc URL & http://hdl.handle.net/2115/66316 \\
\hline Rights & ○ 2016 The Japan Society of A pplied Physics \\
\hline Type & article (author version) \\
\hline File Information & RP160196.pdf \\
\hline
\end{tabular}

Instructions for use 


\title{
Transient change in the shape of premixed burner flame with the superposition of pulsed dielectric barrier discharge
}

\author{
Kazunori Zaima and Koichi Sasaki*
}

Division of Quantum Science and Engineering, Hokkaido University, Sapporo 060-8628, Japan

\begin{abstract}
We investigated the transient phenomena in a premixed burner flame with the superposition of a pulsed dielectric barrier discharge (DBD). The length of the flame was shortened by the superposition of DBD, indicating the activation of combustion chemical reactions with the help of the plasma. In addition, we observed the modulation of the top position of the unburned gas region and the formations of local minimums in the axial distribution of the optical emission intensity of $\mathrm{OH}$. These experimental results reveal the oscillation of the rates of combustion chemical reactions as a response to the activation by pulsed DBD. The cycle of the oscillation was $0.18-0.2 \mathrm{~ms}$, which could be understood as the eigenfrequency of the plasma-assisted combustion reaction system.
\end{abstract}

\section{Introduction}

Conventional combustion is a series of chemical reactions in thermodynamic equilibrium, where the rates of reactions are essentially determined by the gas temperature. Heating the gas temperature works to enhance the rates of combustion chemical reactions, but the high gas temperature results in the emission of nitrogen oxides $\left(\mathrm{NO}_{x}\right)$ owing to the oxidation of molecular nitrogen. The emission of thermal $\mathrm{NO}_{x}$ becomes problematic when the gas temperature exceeds $1800 \mathrm{~K} .{ }^{1)}$ In addition, since the gas heating consumes much energy, it is not an efficient way of enhancing the rates of combustion reactions.

Recently, the activation of combustion chemistry with the help of nonequilibrium plasma (plasma-assisted combustion) is attracting much attention as an innovative method for controlling combustion characteristics. ${ }^{2,3)}$ It has potential in reducing the consumption of fossil fuels and for avoiding global warming by realizing combustion under lean-fuel conditions. ${ }^{4,5)}$ In addition, it is effective for combustion in speedy flow, ${ }^{6-10)}$ for stabilizing a flame, ${ }^{11-13)}$ for increasing burning velocity, ${ }^{14-18)}$ for improving ignition characteristics, ${ }^{19-25)}$ and for the use of alternative fuels.

The principal concept of plasma-assisted combustion is to utilize high-energy electrons

*E-mail: sasaki@qe.eng.hokudai.ac.jp 
in nonequilibrium plasma to produce reactive species via electron impact dissociation, ionization, and excitation. In other words, plasma-assisted combustion aims to shift the combustion chemistry to a nonequilibrium one where high rates of chemical reactions are expected while maintaining the gas temperature. However, the concrete role of high-energy electrons in plasma-assisted combustion was not clarified from the fundamental point of view, in contrast to the progress of application-oriented research. Several researchers have investigated the kinetic mechanisms of plasma-assisted combustion by experiments as well as numerical simulations, and these efforts converge into the common understanding on the importance of atomic oxygen, which is produced by electron impact processes, as the origin of activated combustion reactions. ${ }^{3,26-28)}$ In our recent works, we also pointed out the importance of atomic oxygen produced in the preheating zone of a premixed burner flame. ${ }^{29,30)}$

The understanding on the importance of atomic oxygen is insufficient to optimize practical systems of plasma-assisted combustion. Our recent work shows the importance of atomic oxygen in a limited part of the flame (the preheating zone), but we observe changes in combustion characteristics in a larger volume of the flame. ${ }^{31)}$ Atomic oxygen produced by electron impact processes can act as the origin of activated combustion chemistry, but we should understand how the effects of atomic oxygen in the preheating zone propagate into the larger volume of the flame.

In this work, we have shifted our interest from the bottom to the top of the plasma-assisted premixed burner flame. The bottom part is the region with the direct superposition of the plasma, while the top of the flame is separated from the plasma by a distance of $\sim 40 \mathrm{~mm}$. The two regions are connected by gas flow and the propagation of the flame zone. We have observed the transient change in the shape of the flame, which may include the propagation physics of the effects of atomic oxygen produced by electron impact processes in the bottom part of the flame. The experimental results indicate the oscillation in the rates of combustion reactions. The oscillation frequency is a useful hint for identifying the key reaction in nonequilibrium combustion chemistry.

\section{Experimental procedure}

The schematic of the premixed burner, which is combined with the system of dielectric barrier discharge (DBD), is shown in Fig. 1. We employed the $\mathrm{CH}_{4} / \mathrm{O}_{2} / \mathrm{Ar}$ mixture for producing a premixed flame. The reason for the use of Ar instead of $\mathrm{N}_{2}$ was to avoid the optical emission of the $\mathrm{N}_{2}$ second positive system, which contaminated the optical emission spectrum of the $\mathrm{OH} \mathrm{A}{ }^{2} \Sigma^{+}-X^{2} \Pi$ transition. The use of Ar may emphasize the activation of combustion 
reactions with the help of $\mathrm{DBD}$, since the electron density in the Ar-based plasma is expected to be higher than that in the $\mathrm{N}_{2}$-based plasma. In addition, the combustion chemistry in the $\mathrm{CH}_{4} / \mathrm{O}_{2} / \mathrm{Ar}$ mixture could be different from that in the $\mathrm{CH}_{4} / \mathrm{O}_{2} / \mathrm{N}_{2}$ mixture since $\mathrm{N}_{2}$ is weakly involved in the reaction system. In spite of these problems, in this work, we chose the $\mathrm{CH}_{4} / \mathrm{O}_{2} / \mathrm{Ar}$ mixture to observe the optical emission of the $\mathrm{OH} \mathrm{A}{ }^{2} \Sigma^{+}-\mathrm{X}^{2} \Pi$ transition clearly. The flow rates of $\mathrm{CH}_{4}, \mathrm{O}_{2}$, and $\mathrm{Ar}$ were controlled at $0.38,1.0$, and $5.6 \mathrm{slm}$, respectively, using mass flow controllers. The equivalence ratio was 0.76 . The burner was made of brass and had a $12 \mathrm{~mm}$ outer diameter. It had a main nozzle of $2 \mathrm{~mm}$ diameter at the center, and eight subnozzles of $1.7 \mathrm{~mm}$ diameter surrounding the main nozzle. ${ }^{32)}$ Considering the inside structure of the gas-feed lines, the flow speed of the mixed gas from the main nozzle was estimated to be $26.6 \mathrm{~m} / \mathrm{s}$. A flame of approximately $85 \mathrm{~mm}$ length was obtained under these experimental conditions.

The burner was fixed on a dielectric base plate. The side of the flame was covered with a quartz tube with inner and outer diameters of 7 and $10 \mathrm{~mm}$, respectively. The bottom of the quartz tube was placed at a distance of $12 \mathrm{~mm}$ from the burner nozzle, and the gap between the burner nozzle and the quartz tube was used for diagnostics. The length of the quartz tube was $65 \mathrm{~mm}$, and we observed the top part of the flame above the quartz tube. A 10-mm-high aluminum electrode was attached on the outside of the quartz tube, and it was connected to a high-voltage power supply. The burner was electrically grounded. The waveform of the applied voltage was rectangular with a rise/fall rate of $0.16 \mathrm{kV} / \mu \mathrm{s}$. Asymmetric DBD was produced inside the quartz tube and was superposed onto the flame using this experimental configuration. The discharge power estimated from the V-Q Lissajous curve was less than 10 $\mathrm{W}$, whereas the combustion chemical reaction yielded a chemical power of $250 \mathrm{~W}$.

The images of optical emission intensities from the top (68 $\leq h \leq 96 \mathrm{~mm}$ ) and bottom $(0 \leq h \leq 20 \mathrm{~mm})$ parts of the flame were captured using a charge-coupled device camera with a gated image intensifier (ICCD camera). An interference filter with the transmission at $315 \pm$ $15 \mathrm{~nm}$ was placed in front of the ICCD camera to detect the optical emission corresponding to the $\mathrm{A}^{2} \Sigma^{+}-\mathrm{X}^{2} \Pi$ transition of $\mathrm{OH}$. The gate width of the ICCD camera was set at $50 \mu \mathrm{s}$, and the timing of the gate opening was synchronized with the waveform of the applied voltage. The optical emission image was accumulated on the ICCD camera 3000 times.

Laser-induced fluorescence (LIF) imaging spectroscopy was employed to estimate the spatial distribution of the ground-state $\left(\mathrm{X}^{2} \Pi\right) \mathrm{OH}$ radical density. A tunable laser beam obtained from an optical parametric oscillator (OPO), which was operated at a repetition rate of $10 \mathrm{~Hz}$, was injected into the top part of the flame after arranging the beam shape to be planar 
using two cylindrical lenses. We chose the $\mathrm{X}^{2} \Pi\left(v^{\prime \prime}=0\right)-\mathrm{A}^{2} \Sigma^{+}\left(v^{\prime}=0\right)$ transition at 309.24 $\mathrm{nm}$, which corresponded to the $\mathrm{Q}_{1}$ branch from the rotational state with $J^{\prime \prime}=8$, to excite ground-state $\mathrm{OH}$ radicals. Many rotational states of $\mathrm{A}^{2} \Sigma^{+}\left(v^{\prime}=0\right)$ were populated by the rotational energy transfer, and the LIF emission at the $\mathrm{X}^{2} \Pi\left(v^{\prime \prime}=0\right)-\mathrm{A}^{2} \Sigma^{+}\left(v^{\prime}=0\right)$ transition was captured using the ICCD camera via the interference filter with the transmission at $315 \pm 15$ $\mathrm{nm}$. The spatial distribution of the LIF intensity did not provide an accurate spatial distribution of the $\mathrm{OH}\left(\mathrm{X}^{2} \Pi\right)$ density, since the LIF emission was affected by the spatial distribution of the rotational temperature. ${ }^{33,34)}$ However, in this work, the dynamics of the $\mathrm{OH}\left(\mathrm{X}^{2} \Pi\right)$ density was estimated from the spatial distribution of the LIF intensity. The oscillation timing of the OPO laser was synchronized with the waveform of the applied voltage.

\section{Results}

Figure 2(a) shows the waveforms of the discharge voltage and the discharge current. The frequency of the discharge voltage was $1 \mathrm{kHz}$. The discharge current was averaged for 512 cycles on a digital oscilloscope to obtain the waveform shown in Fig. 2(a). The rising phase of the voltage induced a single current pulse, while we observed three current pulses in the falling phase. The interval between the current pulses was $0.04 \mathrm{~ms}$. Although the duration of the current pulse in a single cycle was roughly $5 \mu \mathrm{s}$, the average current waveforms had longer durations, since the jitter in the discharge current pulse was unavoidable in DBD. The temporal variation of the optical emission intensity of $\mathrm{OH}$, which was observed in the bottom part of the flame ( $h=5 \mathrm{~mm}$ ), is shown in Fig. 2(b). The vertical axis of Fig. 2(b) is normalized by the optical emission intensity in the absence of DBD. As shown in the figure, the optical emission intensity of $\mathrm{OH}$ is enhanced at the timing of the current pulse.

Figure 3(a) shows the optical emission image of the top part of the flame (68 $\leq h \leq$ $96 \mathrm{~mm})$ in the absence of DBD, while we observed the optical emission images shown in Figs. 3(b)-3(k) in the presence of DBD at various phases of the applied voltage. The times indicated in the figures show the initiating timing of the gate opening of the ICCD camera, and they correspond to the horizontal axis of Fig. 2. The top of the quartz tube is located at $h=77 \mathrm{~mm}$. The optical emission observed at $0.1 \leq t \leq 0.4 \mathrm{~ms}$ has another component with a wider horizontal distribution when $68 \leq h \leq 77 \mathrm{~mm}$. This optical emission is due to the second positive system of molecular nitrogen in air, and was caused by the discharge along the outside surface of the quartz tube. As shown in Figs. 3(b)-3(k), we observed the temporal variation in the flame length in the presence of DBD. In addition, we observed the formation of local minimums in the axial distribution of the optical emission intensity. As illustrated by 
the oblique broken lines in the figure, the local minimums moved toward the upper side of the vertical direction at a constant speed. Figures 4(a) and 4(b) show the temporal variations of the flame length and the positions of local minimums, respectively. The dotted line illustrated in Fig. 4(a) shows the flame length in the absence of DBD. The top of the flame was defined by the position that had half of the optical emission intensity at the position just above the upper edge of the quartz tube. The ambiguity caused by the optical emission intensity of the discharge along the outside surface of the quartz tube $(0.1 \leq t \leq 0.4 \mathrm{~ms})$ was compensated by subtracting the intensity at $h<77 \mathrm{~mm}$ from the optical emission intensity just above the upper edge of the quartz tube. The labels (i)-(vi) indicated in Fig. 4(b) correspond to the oblique broken lines with the same labels in Fig. 3. The dotted line illustrated in Fig. 4(b) shows the flow speed of the mixed gas. The propagation speed of the local minimums roughly agreed with the flow speed of the gas.

Figure 5(a) shows the image of LIF observed at the top of the flame in the absence of DBD. The observation area of the LIF measurement is illustrated by the rectangle in Fig. 3(a). A triangular area with a weak LIF intensity was observed at $82 \leq h \leq 85 \mathrm{~mm}$. This region with a lower $\mathrm{OH}$ radical density corresponded to the unburned gas region. In the presence of DBD, as shown in Figs. 5(b)-5(g), we observed the change in the top position of the unburned gas region. At $t=0.7 \mathrm{~ms}$, as shown in Fig. 5(b), the top of the unburned gas region moved toward the bottom side. The unburned gas region was stretched at $t=0.8 \mathrm{~ms}$, as shown in Fig. 5(c). The lower part of the unburned gas region moved downward at $t=0.9 \mathrm{~ms}$, while the top part of the unburned gas region continued to move upward, resulting in the isolated patch of unburned gas at around $h \simeq 90 \mathrm{~mm}$. A similar phenomenon was repeated at $1 \leq t \leq 1.2$ ms, as shown in Figs. 5(e)-5(g). As illustrated by the broken oblique lines in Fig. 5, the speed of the upward movement of the isolated unburned gas region coincided well with the flow speed of the gas.

Similar experiments to those corresponding to Figs. 2-5 were repeated at a lower frequency of the applied voltage $(50 \mathrm{~Hz})$. The waveforms of the discharge voltage and the discharge current are shown in Fig. 6(a), while Fig. 6(b) shows the temporal variation of the optical emission intensity at the bottom part of the flame $(h=5 \mathrm{~mm})$. The expanded waveform of the discharge current was similar to that shown in Fig. 2(a), and three current pulses with an interval of $0.04 \mathrm{~ms}$ were observed in the falling phase of the discharge voltage. The vertical axis in Fig. 6(b) is normalized by the optical emission intensity in the absence of DBD. It is known from Fig. 6 that pulsed plasmas were produced upon the alternation of the polarity of the applied voltage $(t=0$ and $10 \mathrm{~ms})$. 
Figure 7 shows the temporal variation of the flame length within one cycle of the $50 \mathrm{~Hz}$ discharge. The time axis corresponds to the horizontal axis of Fig. 6, and the dotted line illustrated in the figure shows the flame length in the absence of DBD. We observed the shortening of the flame length, and the shortest flame length was observed at $t \simeq 2.6$ and $12.7 \mathrm{~ms}$. The continuous shortening of the flame length was observed after the shortest flame length, and the continuous shortening was terminated upon the alternation of the polarity of the applied voltage.

The formations of local minimums in the axial distribution of the optical emission intensity, which were similar to those shown in Fig. 3, were observed in the $50 \mathrm{~Hz}$ discharge. The local minimums were observed at the timing of the shortest flame length. Figure 8 shows the movements of the local minimums together with the temporal variation of the flame length. The dotted lines show the flow speed of the mixed gas. The moving speeds of the local minimums coincided well with the flow speed of the gas.

\section{Discussion}

It is widely understood that the length of the steady-state premixed burner flame reflects the rate of the combustion chemical reaction. ${ }^{35)}$ The transport length of the unburned gas from the nozzle becomes shorter with a higher rate of combustion reactions, since the fuel is consumed in the lower part of the flame. Therefore, the high rates of combustion reactions result in a short flame length. In a previous paper, we reported the shortening of the flame length by the superposition of DBD as a function of the amount of high-energy electrons. ${ }^{31)}$ This result was obtained on the basis of time-integrated pictures of the flame. However, the shortened flame length was not stationary, and in the present paper, we report the transient change in the flame shape when pulsed DBD is superposed onto the premixed burner flame.

A point to be discussed is the delay time between the pulsed discharge and the shortening of the flame length. As shown in Fig. 7, the shortest flame length was observed at approximately $2.7 \mathrm{~ms}$ after the pulsed production of the plasma. If the transport is due to the gas flow, the delay time of $\sim 2.7 \mathrm{~ms}$ corresponds to the transport length of $\sim 72 \mathrm{~mm}$ (the gas flow speed is $26.6 \mathrm{~m} / \mathrm{s}$ ), which is close to the shortened flame length. This suggests that the region with activated combustion reactions is formed in the bottom part of the flame, and the activated region is transported upward along the gas flow.

It is noted that we observed two or three local minimums in the axial distribution of the optical emission intensity, as shown in Fig. 8, when the frequency of the applied voltage was $50 \mathrm{~Hz}$. The interval between the local minimums was approximately $0.18 \mathrm{~ms}$, which 
was much longer than the interval between the current pulses during the falling phase of the discharge voltage $(0.04 \mathrm{~ms})$. Since chemiluminescence is the predominant mechanism of the optical emission of $\mathrm{OH},{ }^{36}$ ) it is considered that combustion reactions are less efficient at the local minimums. The local minimums moved upward with the gas flow speed, suggesting that they originate from the lower part of the flame. In other words, in the lower part of the flame, the rates of combustion reactions become less efficient temporally with the interval of $\sim 0.18$ ms. The less efficient reactions may be due to the excessive consumption of oxidizers, which is caused by the overshooting of the rates of combustion reactions by the superposition of the pulsed plasma. As reported in a previous paper, ${ }^{30)}$ we observed the oscillation of the density of atomic oxygen in the preheating zone of the bottom part of the DBD-assisted flame. However, the oscillation frequency of the atomic oxygen density in the bottom part was much higher than the interval of the local minimums observed in the top part of the flame. The formations of the local minimums were observed repetitively, as shown in Figs. 3 and 4(b), when the frequency of the applied voltage was $1 \mathrm{kHz}$. The average of the intervals among the local minimums was $\sim 0.2 \mathrm{~ms}$ in the $1 \mathrm{kHz}$ discharge.

The modulation of the top position of the unburned gas region was observed by the LIF measurement, as shown in Fig. 5. The downward movement of the top of the unburned gas was observed at 0.7 [Fig. 5(b)], 0.9 [Fig. 5(d)], and $1.1 \mathrm{~ms}$ [Fig. 5(f)], while the plasmas were produced at $0.02 \lesssim t \lesssim 0.1$ and $0.52 \lesssim t \lesssim 0.68 \mathrm{~ms}$, as shown in Fig. 2. The shortening of the unburned gas region at $t=0.7,0.9$, and $1.1 \mathrm{~ms}$ was followed by elongation at $t=0.8$, 1 , and $1.2 \mathrm{~ms}$, respectively, indicating clearly that the rates of combustion reactions oscillate in the lower part of the flame at a cycle of $0.2 \mathrm{~ms}$. This phenomenon is closely related to the formation of local minimums in the axial distribution of the optical emission intensity, since the modulation cycle $(0.2 \mathrm{~ms})$ of the top position of the unburned gas region is equal to the interval among the local minimums. The present experimental results reveal the existence of overshooting phenomena in the rates of combustion reactions when pulsed DBD is superposed onto the steady-state premixed burner flame. The cycle of $0.18-0.2 \mathrm{~ms}$ could be understood as the eigenfrequency of the chemical reaction system in the DBD-assisted flame. The formation of local minimums in the axial distribution of the optical emission intensity was also observed at the top of the flame when we terminated the irradiation of the microwave power to the bottom part of the flame. ${ }^{32)}$ However, the cycle of the formation of the local minimums was different from that observed in the present experiment, and was approximately 0.1 ms. The irradiation of the microwave power caused electron heating in the flame, and it did not result in discharges, which is the principal difference between the two experiments. In 
addition, the gas flow speed in the microwave irradiation experiment was $20.9 \mathrm{~m} / \mathrm{s}$, which is slower than the gas flow speed in the present experiment.

Finally, we give a brief discussion on unexpected results included in Fig. 7. As mentioned above, the delay time between the pulsed production of the plasma ( $t=0$ and $10 \mathrm{~ms}$ ) and the shortest flame length $(t \simeq 2.6$ and $12.7 \mathrm{~ms}$ ) is explained by the transport of the region with activated combustion reactions along the gas flow. An unexpected result is the continuous shortening of the flame length beyond its previous shortest length until the next alternation of the polarity of the applied voltage $(2.6 \lesssim t \leq 10$ and $12.7 \lesssim t \leq 20 \mathrm{~ms})$. Considering the continuous gas flow at a speed of $26.6 \mathrm{~m} / \mathrm{s}$, the gas in the flame is refreshed completely after the shortest flame length. In addition, no plasmas are produced until the next alternation of the applied voltage. Therefore, the continuous shortening beyond its previous shortest flame length is not caused by plasma-assisted effects. The effect of the electric field could be the mechanism behind the continuous shortening at $2.6 \lesssim t \leq 10$ and $12.7 \lesssim t \leq 20 \mathrm{~ms}$. However, since the flame lengths at $0 \leq t \lesssim 2 \mathrm{~ms}$ and $10 \leq t \lesssim 12 \mathrm{~ms}$ are the same as that without the superposition of DBD, it is considered that the electric field alone cannot change the flame length. A possibility is the effect of electrical charges on the surface of the quartz tube. The effect of electrical charges could also explain the elongation of the flame length at $t=0$ and $10 \mathrm{~ms}$, since the electrical charges on the quartz tube are canceled upon the alternation of the polarity of the applied voltage. However, the elongations of the flame length at $t=0$ and 10 ms are sudden, which is another unexpected result. The electrical charge on the surface of the quartz tube may be limited in the axial region corresponding to the aluminum electrode $(25 \leq z \leq 35 \mathrm{~mm})$. Hence, we could observe a delay time between the cancellation of the electrical charges and the elongation of the flame length, since there is a distance of $42 \mathrm{~mm}$ between the upper side edge of the electrode and the top of the quartz tube. However, we observed no delay time between the alternation of the polarity of the applied voltage and the elongation of the flame length. Further investigations are necessary to understand the mechanism of the continuous shortening and the sudden elongation of the flame length.

\section{Conclusions}

In this work, we focused on the transient phenomena in the shape of a premixed burner flame with the superposition of pulsed DBD. The flame length was shortened by the superposition of $\mathrm{DBD}$, indicating the activation of combustion reactions in the DBD-assisted flame. However, we also observed less efficient combustion reactions temporally, which was evident from the formation of local minimums in the axial distribution of the optical emission 
intensity of $\mathrm{OH}$ and the modulation of the top position of the unburned gas region. These phenomena may be a result of overshooting in the rates of combustion chemical reactions in the transition between equilibrium and nonequilibrium combustion chemistries. The experimental results indicate that the oscillation of the rates of combustion chemical reactions occurs at a cycle of 0.18-0.2 ms, which could be understood as the eigenfrequency of the chemical reaction system, and is a useful hint for identifying the key reaction in plasma-assisted combustion.

\section{Acknowledgment}

This work was supported by JSPS KAKENHI Grant Number 25286078. 


\section{References}

1) Z. R. Ismagilov and M. A. Kerzhntsev, Catal. Rev. Sci. Eng. 32, 51 (1990).

2) S. M. Starikovskaia, J. Phys. D 39, R265 (2006).

3) A. Starikovskiy and N. Aleksandrov, Prog. Energy Combust. Sci. 39, 61 (2013).

4) Y. Ikeda, A. Nishiyama, Y. Wachi, and M. Kaneko, SAE Int. 2009-01-1050 (2009).

5) Y. Ikeda, A. Nishiyama, H. Katano, M. Kaneko, and J. Han, SAE Int. 2009-01-1049 (2009).

6) S. B. Leonov, D. A. Yarantsev, A. P. Napartovich, and I. V. Kochetov, IEEE Trans. Plasma Sci. 34, 2514 (2006).

7) I. Esakov, L. P. Grachev, K. V. Khodataev, V. A. Vinogradov, and D. M. van Wie, IEEE Trans. Plasma Sci. 34, 2497 (2006).

8) S. V. Leonov and D. A. Yarantsev, Plasma Sources Sci. Technol. 16, 132 (2007).

9) T. Ombrello, X. Qin, and Y. Ju, AIAA J. 44, 142 (2006).

10) T. Ombrello, Y. Ju, and A. Fridman, AIAA J. 46, 2424 (2008).

11) G. Pilla, D. Galley, D. A. Kacoste, F. Lacas, D. Veynante, and C. O. Laux, IEEE Trans. Plasma Sci. 34, 2471 (2006).

12) X. Rao, S. Hammack, T. Lee, C. Carter, and I. B. Matveev, IEEE Trans. Plasma Sci. 38, 3265 (2010).

13) Q. L. L. Pham, D. A. Lacoste, and C. O. Laux, IEEE Trans. Plasma Sci. 39, 2264 (2011).

14) S. Stange, Y. Kim, V. Ferreri, L. A. Rosocha, and D. M. Coates, IEEE Trans. Plasma Sci. 33, 316 (2005).

15) K. Shinohara, N. Takada, and K. Sasaki, J. Phys. D 42, 182008 (2009).

16) E. S. Stockman, S. H. Zaidi, R. B. Miles, C. D. Carter, and M. D. Ryan, Combust. Flame 156, 1453 (2009).

17) T. Ombrello, S. H. Won, Y. Ju, and S. Williams, Combust. Flame 157, 1906 (2010).

18) T. Ombrello, S. H. Won, Y. Ju, and S. Williams, Combust. Flame 157, 1916 (2010).

19) S. Y. Pancheshnyi, D. A. Lacoste, A. Bourdon, and C. O. Laux, IEEE Trans. Plasma Sci. 34, 2478 (2006).

20) N. L. Aleksandrov, S. V. Kindysheva, I. N. Kosarev, S. M. Starikovskaia, and A. Y. Starikovskii, Proc. Combust. Inst. 32, 205 (2009).

21) G. Lou, A. Bao, M. Nishihara, S. Keshav, Y. G. Utkin, J. W. Rich, W. R. Lempert, and I. V. Adamovich, Proc. Combust. Inst. 31, 3327 (2007). 
22) A. Bao, Y. G. Utkin, S. Keshav, G. Lou, and I. V. Adamovich, IEEE Trans. Plasma Sci. 35, 1628 (2007).

23) W. Sun, M. Uddi, T. Ombrello, S. H. Won, C. Carter, and Y. Ju, Proc. Combust. Inst. 33, 3211 (2011).

24) W. Sun, S. H. Won, T. Ombrello, C. Carter, and Y. Ju, Proc. Combust. Inst. 34, 847 (2013).

25) L. Wu, J. Lane, N. P. Cernansky, D. L. Miller, A. Fridman, and A. Y. Starikovskiy, Proc. Combust. Inst. 33, 3219 (2011).

26) W. Kim, M. G. Mungal, and M. A. Cappelli, Combust. Flame 157, 374 (2010).

27) I. N. Kosarev, N. L. Aleksandrov, S. V. Kindysheva, S. M. Starikovskaia, and A. Y. Starikovskii, Combust. Flame 156, 221 (2009).

28) W. Sun, M. Uddi, T. Ombrello, S. H. Won, C. Carter, and Y. Ju, Proc. Combust. Inst. 33, 3211 (2011).

29) K. Zaima and K. Sasaki, Jpn. J. Appl. Phys. 53, 110309 (2014).

30) K. Zaima, H. Akashi, and K. Sasaki, Jpn. J. Appl. Phys. 55, 016201 (2016).

31) K. Zaima and K. Sasaki, Jpn. J. Appl. Phys. 53, 066202 (2014).

32) K. Sasaki and K. Shinohara, J. Phys. D 45, 455502 (2012).

33) H. Ishigame, S. Nishiyama, and K. Sasaki, Jpn. J. Appl. Phys. 54, 01 AF02 (2015).

34) K. Sasaki, H. Ishigame, and S. Nishiyama, Eur. Phys. J.: Appl. Phys. 71, 20807 (2015).

35) A. G. Gaydon and H. G. Wolfhard, Flames: Their Structure, Radiation and Temperature (Chapman and Hall, London, 1974) 4th ed.

36) K. H. Becker and D. Kley, Chem. Phys. Lett. 4, 62 (1969). 


\section{Figure captions}

Figure 1 Schematic of premixed burner flame with superposition of dielectric barrier discharge.

Figure 2 (a) Waveform of the discharge voltage and the discharge current and (b) temporal variation of the optical emission intensity of $\mathrm{OH}$ in the bottom part $(h=5 \mathrm{~mm}$ ) of the flame, when the frequency of the applied voltage was $1 \mathrm{kHz}$.

Figure 3 Optical emission images of the top part of the flame observed (a) in the absence of DBD and (b)-(k) in the presence of DBD at various phases of the applied voltage. The times indicated in (b)-(k) correspond to the horizontal axis of Fig. 2.

Figure 4 Temporal variations of (a) flame length and (b) the positions of local minimums in the axial distribution of the optical emission intensity of $\mathrm{OH}$.

Figure 5 Images of laser-induced fluorescence of $\mathrm{OH}$ at the top of the flame observed (a) in the absence of DBD and (b)-(g) in the presence of DBD at various phases of the applied voltage. The times indicated in (b)-(g) correspond to the horizontal axis of Fig. 2.

Figure 6 (a) Waveform of the discharge voltage and the discharge current and (b) temporal variation of the optical emission intensity of $\mathrm{OH}$ in the bottom part ( $h=5 \mathrm{~mm}$ ) of the flame, when the frequency of the applied voltage was $50 \mathrm{~Hz}$.

Figure 7 Temporal variation of the flame length when the frequency of the applied voltage was $50 \mathrm{~Hz}$.

Figure 8 Temporal variations of the flame length and the positions of the local minimums when the frequency of the applied voltage was $50 \mathrm{~Hz}$. 


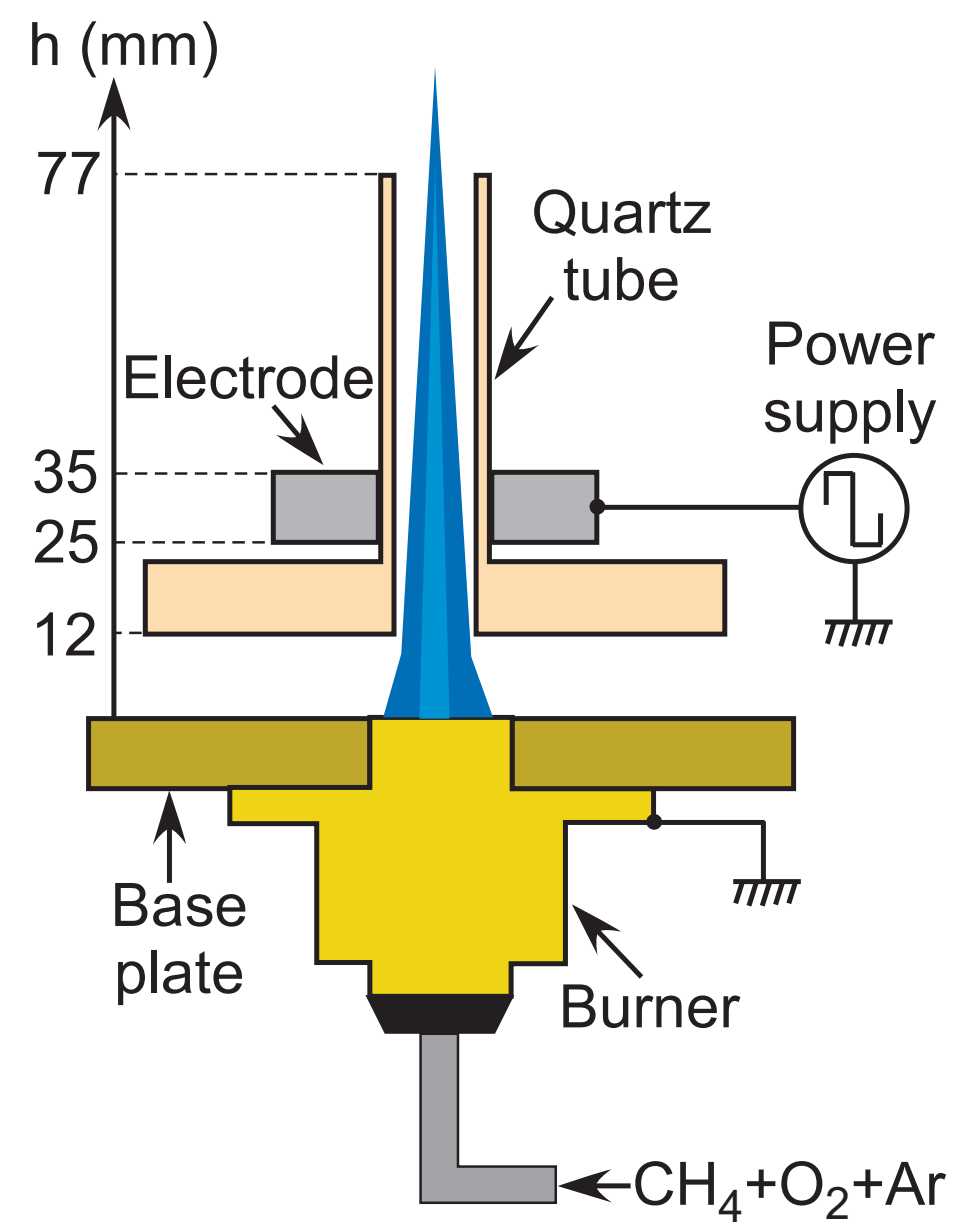

Fig. 1. Schematic of premixed burner flame with superposition of dielectric barrier discharge. 


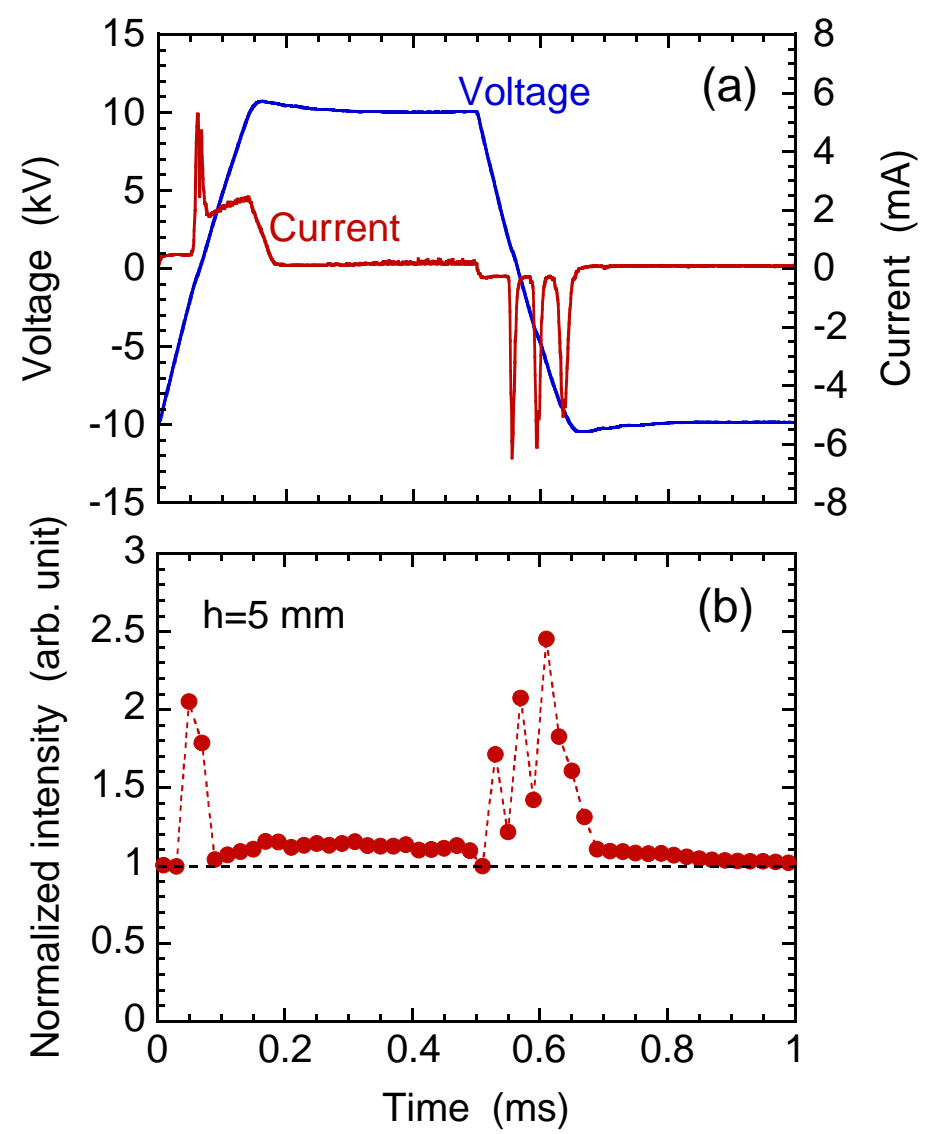

Fig. 2. (a) Waveform of the discharge voltage and the discharge current and (b) temporal variation of the optical emission intensity of $\mathrm{OH}$ in the bottom part $(h=5 \mathrm{~mm})$ of the flame, when the frequency of the applied voltage was $1 \mathrm{kHz}$. 


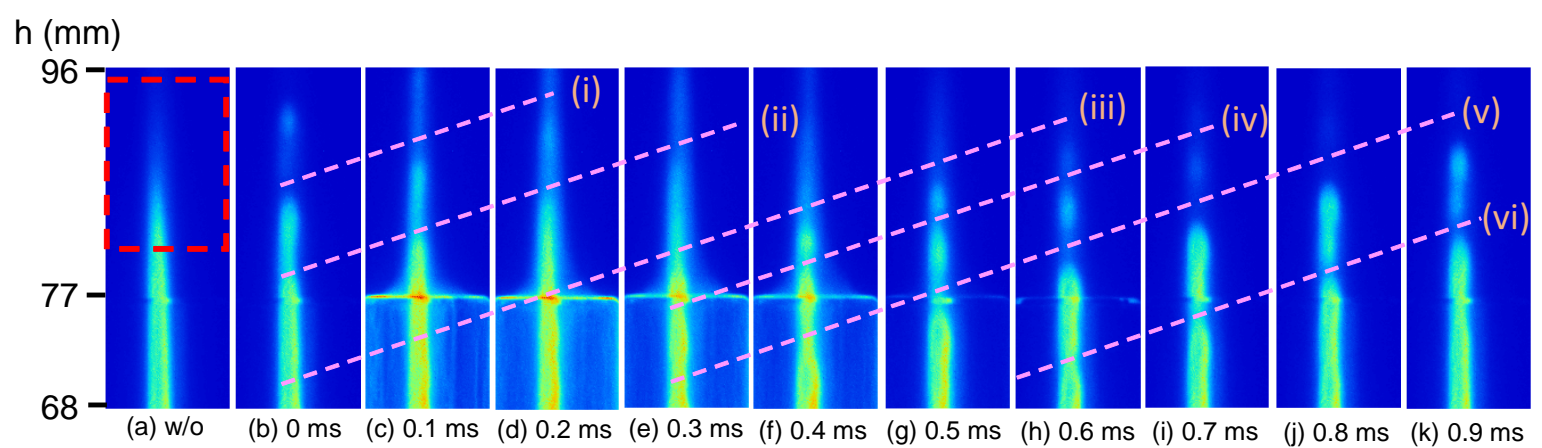

Fig. 3. Optical emission images of the top part of the flame observed (a) in the absence of DBD and (b)-(k) in the presence of DBD at various phases of the applied voltage. The times indicated in (b)-(k) correspond to the horizontal axis of Fig. 2. 


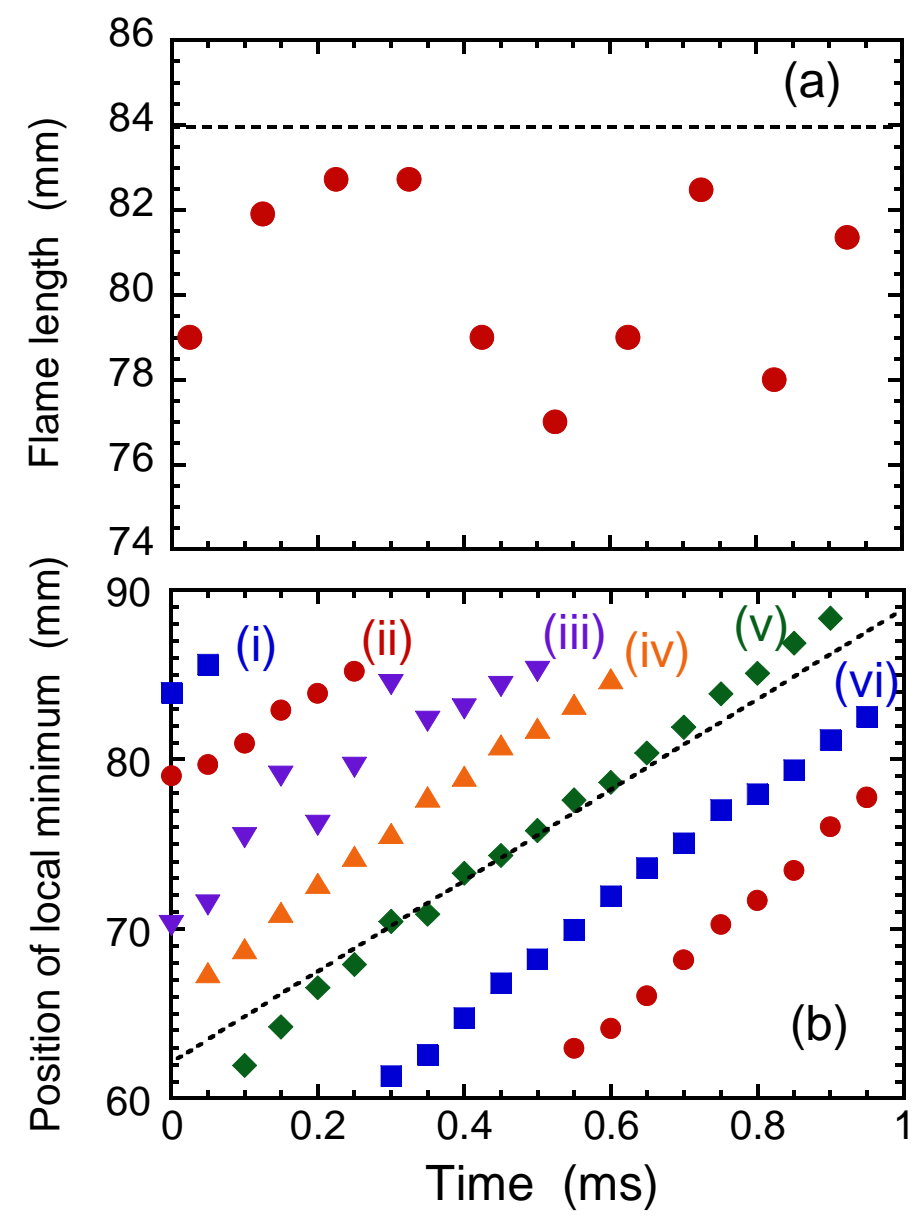

Fig. 4. Temporal variations of (a) flame length and (b) the positions of local minimums in the axial distribution of the optical emission intensity of $\mathrm{OH}$. 


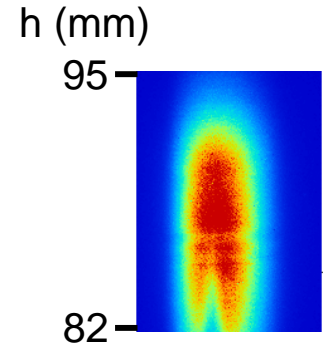

(a) $w / 0$

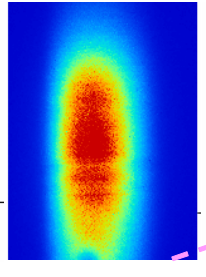

(b) $0.7 \mathrm{~ms}$

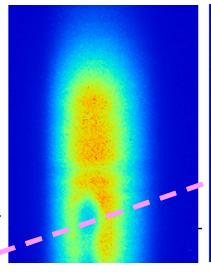

(c) $0.8 \mathrm{~ms}$

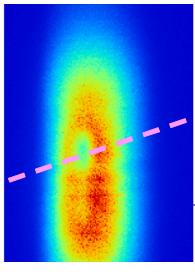

(d) $0.9 \mathrm{~ms}$

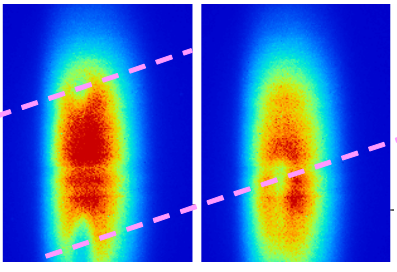

$\begin{array}{lll}\text { (e) } 1 \mathrm{~ms} & \text { (f) } 1.1 \mathrm{~ms}\end{array}$ (0 ms)

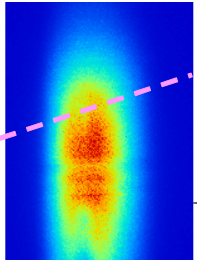

(g) $1.2 \mathrm{~ms}$ (0.2 ms)

Fig. 5. Images of laser-induced fluorescence of $\mathrm{OH}$ at the top of the flame observed (a) in the absence of DBD and (b)-(g) in the presence of DBD at various phases of the applied voltage. The times indicated in (b)-(g) correspond to the horizontal axis of Fig. 2. 


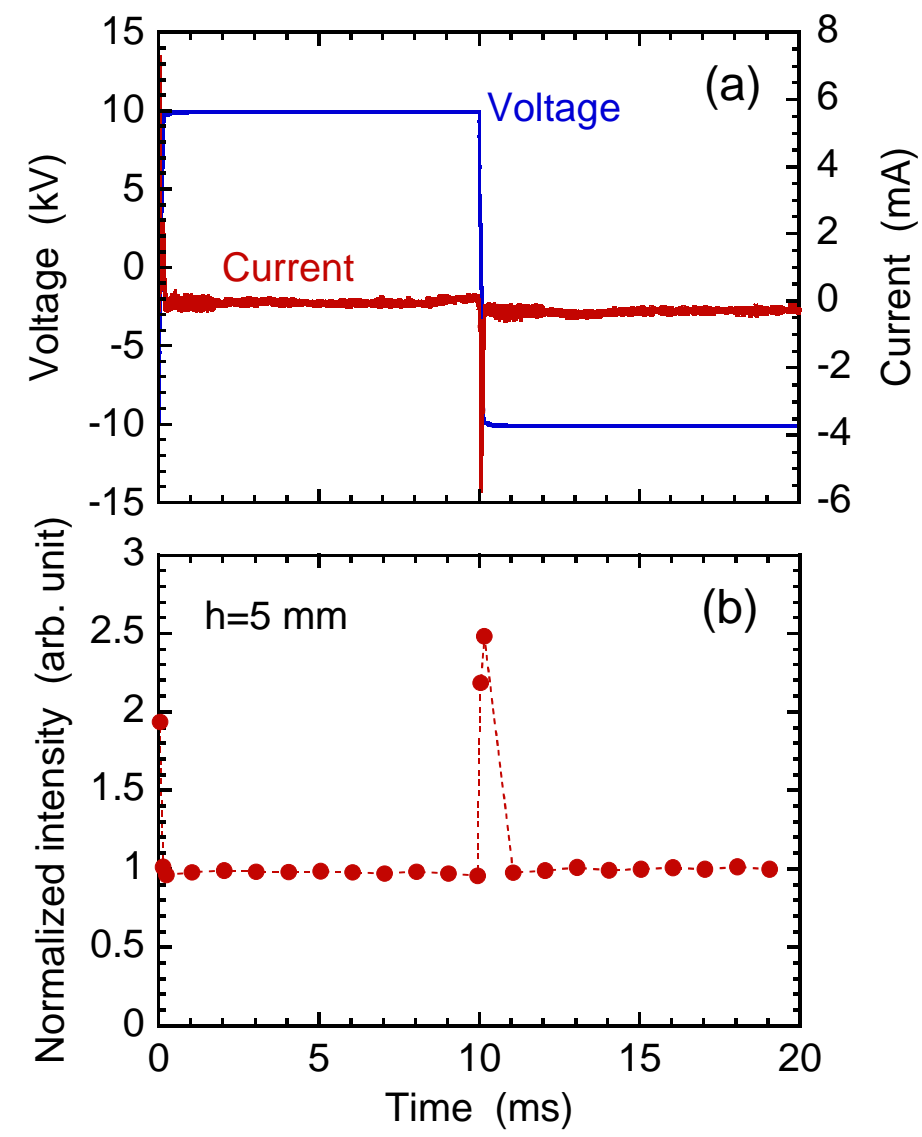

Fig. 6. (a) Waveform of the discharge voltage and the discharge current and (b) temporal variation of the optical emission intensity of $\mathrm{OH}$ in the bottom part $(h=5 \mathrm{~mm})$ of the flame, when the frequency of the applied voltage was $50 \mathrm{~Hz}$. 


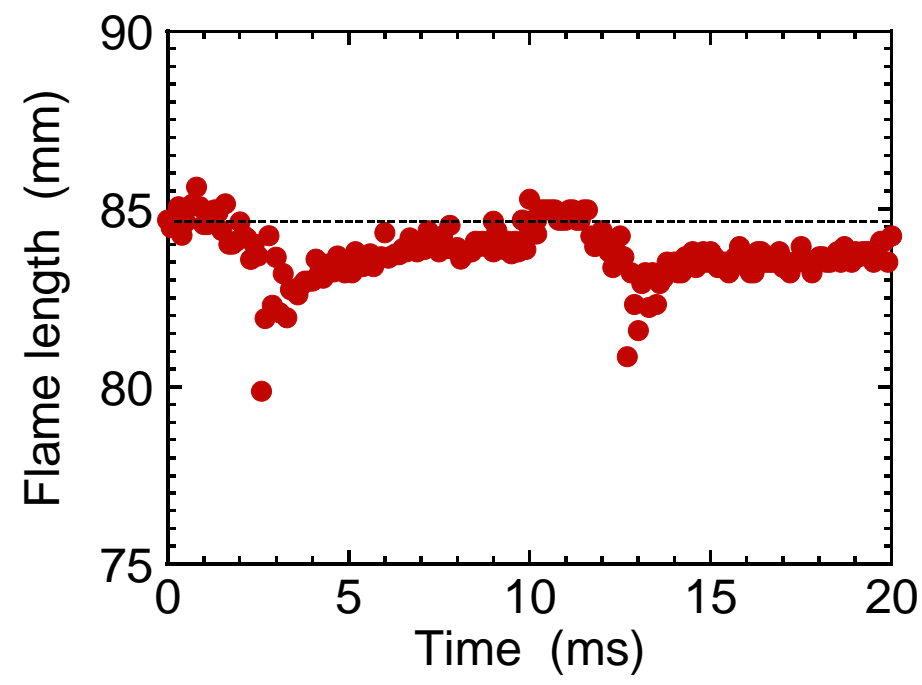

Fig. 7. Temporal variation of the flame length when the frequency of the applied voltage was $50 \mathrm{~Hz}$. 

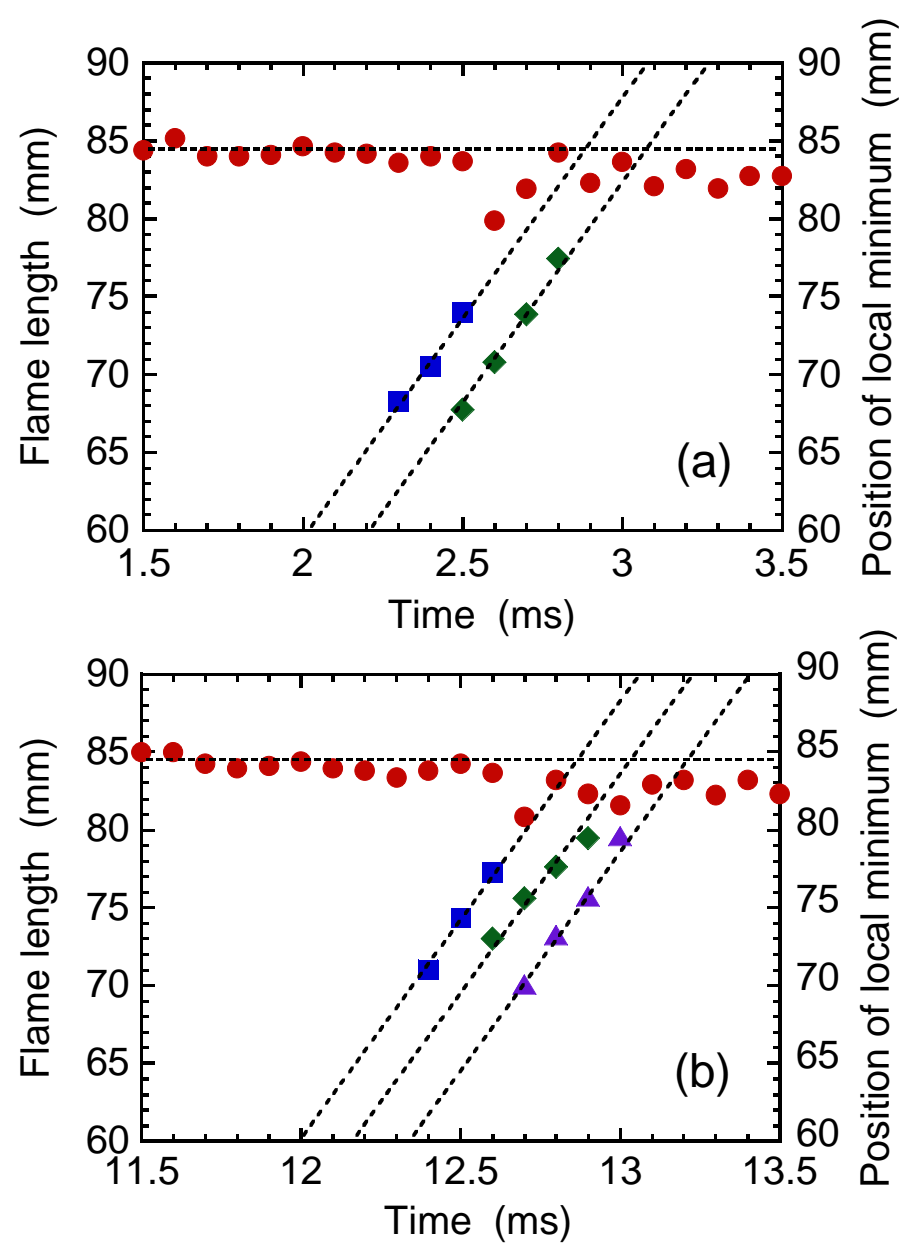

Fig. 8. Temporal variations of the flame length and the positions of the local minimums when the frequency of the applied voltage was $50 \mathrm{~Hz}$. 